\title{
APLICAÇÃO DE GLIFOSATO EM CAMPO NATURALIZADO DE PENSACOLA, PARA ESTABELECIMENTO DE FORRAGEIRAS HIBERNAIS EM SOBRE-SEMEADURA ${ }^{1}$
}

\section{GLYPHOSATE APPLICATION ON NATURALIZED COUNTRY WITH PENSACOLA, FOR OVERSEEDING COOL-SEASON FORAGES}

\author{
Francisco Antonio MARÇALLO 2 \\ Adelino PELISSARI ${ }^{3}$ \\ Anibal de MORAES ${ }^{3}$
}

\begin{abstract}
RESUMO
O presente trabalho foi conduzido na Fazenda Capão Redondo, situada no município de Candói - PR. Foi realizado nos anos de 2000 e 2001, com o objetivo de avaliar a participação da pensacola em campo naturalizado, submetida à aplicação de glifosato para a sobre-semeadura de espécies hibernais, bem como o efeito desta aplicação no restabelecimento da pensacola. O delineamento experimental foi o de blocos ao acaso com cinco tratamentos e duas repetições. Foram sobre-semeados azevém, trevo branco, trevo vermelho e cornichão, após a dessecação da pastagem de pensacola com doses de glifosato. Os tratamentos (T) foram: T1=zero; $\mathrm{T} 2=0,5 ; \mathrm{T} 3=0,75 ; \mathrm{T} 4=1,0 ; \mathrm{T} 5=1,25 \mathrm{~L}_{\text {.ha }}{ }^{-1}$. Para a estimativa da participação da pensacola na matéria seca disponível (MSd), foi utilizada a metodologia Botanal em quatro datas $(08 / 12 / 00 ; 09 / 02 / 01 ; 06 / 06 / 01 ; 20 / 12 / 01)$. Observou-se que no tratamento sem herbicida houve excelente controle da pensacola na época de sobre-semeadura e restabelecimento desta no verão. Concluiu-se que, nas condições em que este trabalho foi desenvolvido, na presença de geada, não foi necessária a aplicação de glifosato para o estabelecimento das espécies em sobre-semeadura. O herbicida glifosato interferiu na participação da pensacola no campo naturalizado sob ação da geada, embora tenha permitido seu restabelecimento. A ação da geada foi suficiente para controlar a pensacola na época que antecede a sobre-semeadura.
\end{abstract}

Palavras-chave: herbicida, campo naturalizado, Paspalum notatum, dessecação, Botanal, geadas.

\begin{abstract}
A field study was conducted at Fazenda Capão Redondo, in Candói - PR, Brazil, to evaluate the participation of the pensacola (Paspalum notatum) on naturalized country, with and without glyphosate application for sod suppression, for overseeding cool-season forages on a pensacola pasture. The specific objective was to evaluate the effect of glyphosate application on subsequent regrowth of the pensacola pasture. The study was conducted during 2000 and 2001 using a randomized complete block design with five treatments and two replications. A seed mixture of Lolium multiflorum, Trifolium repens, Trifolium pratense and Lotus corniculatus was oversown on the pensacola pasture after dessication with different rates of glyphosate. The treatments $(T)$ were: $T 1=0 ; T 2=0.5 ; T 3=0.75$; $\mathrm{T} 4=1.0 ; \mathrm{T} 5=1.25 \mathrm{~L} \mathrm{ha}^{-1}$. The Botanal method was used to estimate the presence of the pensacola in the available dry matter on four dates (Dec-2000, Feb-2001, Jun-2001, Dec-2001). In the treatment without glyphosate, excellent pensacola suppress was observed during the cold months followed by regrowth of pensacola in the summer. Under the conditions of this trial, In the occurrence of hoar, glyphosate application was not necessary for successful establishment of the oversown species, the glyphosate application reduced the presence of pensacola in the naturalized pasture, however has regrowth of pensacola in the summer. In the occurrence of hoar the glyphosate application was not necessary for successful establishment of the oversown species.

Key-words: herbicide, naturalized pasture, Paspalum notatum, dessication, Botanal, hoarfrost.
\end{abstract}

\footnotetext{
${ }^{1}$ Parte da Dissertação de Mestrado do primeiro autor, apresentado no Curso de Pós-Graduação em Agronomia - Produção Vegetal - SCA/UFPR.

${ }^{2}$ Aluno de Doutorado do Curso de Pós-Graduação em Agronomia - Produção Vegetal - SCA/UFPR.

${ }^{3}$ Professor do Curso de Pós-Graduação em Agronomia - Produção Vegetal - SCA/UFPR.
} 


\section{INTRODUÇÃO}

Os campos nativos e os campos naturalizados representam $25 \%$ das pastagens do Estado do Paraná. Apresentam produtividade considerada baixa, mas têm grande potencial de produção, o qual está longe ainda de ser atingido. Existe uma riqueza de espécies nobres nos campos naturais paranaenses. No entanto, a freqüência destas espécies é muito baixa o que torna a composição botânica essencialmente estival, determinando uma grande flutuação estacional no crescimento destes campos e uma evidente limitação de uso no período crítico de inverno. Muitos campos nativos e naturalizados estão sendo substituídos por pastagens exóticas ou culturas anuais, diminuindo a biodiversidade existente.

A degradação das pastagens vem aumentando de forma acentuada, inserindo dúvida na sustentabilidade do sistema de produção animal. Grande parte das áreas de pastagens brasileiras foi formada há muitos anos e encontra-se em avançado estágio degradação. São muitos os fatores que estão relacionados com a degradação das pastagens, mas a lotação animal excessiva e a falta de adubação têm sido os aceleradores do processo de degradação (MACEDO, 2001).

A introdução de espécies hibernais, sobre campo naturalizado, aumenta a produção, valor nutritivo e distribuição estacional da forragem (REIS e FONTANELI, 2000) e pode ser realizada por sobre-semeadura. A sobre-semeadura é uma alternativa que consiste em semear a lanço uma ou mais espécies forrageiras sobre outra pastagem já estabelecida sem a destruição desta (BALL et al., 1991), favorecendo o desenvolvimento sustentável à medida que há uma maior conservação do solo, redução de custos e tempo de implantação, preserva a pastagem e a biodiversidade local (RIZO, 2001), além de possibilitar a utilização de áreas impróprias para o cultivo.

O uso de determinados herbicidas mostra-se eficaz na sobre-semeadura. Estes paralisam o crescimento da pastagem facilitando a emergência, desenvolvimento e o pleno estabelecimento das espécies introduzidas. A desvantagem deste sistema é a possibilidade de prejudicar e/ou eliminar algum componente de interesse. Portanto, a aplicação de herbicidas antes da sobre-semeadura carece de pesquisas que respondam questões que ainda possam deixar dúvidas sobre o sistema, como por exemplo, o restabelecimento da pastagem de verão.

Desta forma, o objetivo do trabalho foi o de avaliar a participação da pensacola (Paspalum notatum var. saurae) existente em campo naturalizado, sobre-semeado com espécies hibernais, após a aplicação de glifosato.

\section{METODOLOGIA}

O experimento foi conduzido no período de abril de 2000 a dezembro de 2001, na Fazenda Capão Redondo, no Município de Candói - PR, situada a 1.095 metros de altitude média. O clima, segundo a classificação Köeppen, é do do tipo Cfb (MAAK, 1968), sendo caracterizado como subtropical úmido, mesotérmico (IAPAR, 1994). A evapotranspiração potencial é superada pela precipitação em todos os meses. A temperatura média anual é de $18^{\circ} \mathrm{C}$ e a precipitação média anual, da região, varia de 1.400 a $1.800 \mathrm{~mm}$.ano ${ }^{-1}$. No ano 2000 ocorreram 17 geadas, das quais 8 foram severas e em 2001 foram registradas 10 geadas de menores intensidades (SIMEPAR, 2002). A insolação média é de 2.200 horas anuais e a umidade relativa do ar de $80 \%$ (IAPAR, 1994). A classificação do solo da área experimental é dada pela associação de Latossolo Bruno Alumínico típico associado ao Cambissolo Háplico Alumínico Tb (EMBRAPA, 1999).

A área experimental foi utilizada desde 1990 em pastejo, data na qual, foi implantada a pensacola (Paspalum notatum var. saurae). Devido à resiliência do campo, a área experimental estava caracterizada como campo naturalizado, no momento da instalação do experimento.

O delineamento experimental utilizado foi o de blocos ao acaso com cinco tratamentos e duas repetições. Este experimento foi conduzido com a ação de geada. A aplicação do herbicida glifosato (360 $\mathrm{g}$ ea. ${ }^{-1}$ ) foi realizada no dia 27 de maio de 2000 e até esta data já havia ocorrido duas geadas amenas (Tabela 1). As geadas mais severas ocorreram no período de 13 de julho a 24 de julho. A calagem foi realizada a lanço, conforme recomendação para sobre-semeadura (COMISSÃO, 1995; VINCENZI, 1998).

Nas parcelas, cada uma com 1,3 ha aproximadamente, foram aplicados os seguintes tratamentos: T1 - sem herbicida (testemunha); T2 aplicação de 0,5 I.ha-1 (180 g ea.ha ${ }^{-1}$ ) de glifosato; T3 aplicação de 0,75 I.ha- $^{-1}$ (270 g ea.ha ${ }^{-1}$ ) de glifosato; T4 - aplicação de 1,0 I.ha-1 (360 g ea.ha-1) de glifosato; T5 - aplicação de 1,25 I.ha-1 (450 g ea.ha-1) de glifosato. Todas as parcelas receberam as mesmas quantidades de adubos e sementes em uma mesma operação, à lanço, realizada em 9 de junho de $2000 \mathrm{com}$ as seguintes quantidades, respectivamente: $18 \mathrm{~kg} \cdot \mathrm{ha}^{-1} \mathrm{de}$ nitrogênio, $120 \mathrm{~kg} \cdot \mathrm{ha}^{-1}$ de fósforo e $90 \mathrm{~kg} \cdot \mathrm{ha}^{-1} \mathrm{de}$ potássio, dado pela recomendação baseada na análise de solo (Tabela 2) e $40 \mathrm{~kg}$ ha $^{-1}$ de azevém (Lolium multiflorum Lam.); 4 kg.ha-1 de trevo vermelho (Trifolium pratense L.); 3 kg.ha-1 de trevo branco (Trifolium repens L.); 4 kg.ha-1 de cornichão (Lotus corniculatus L. cv. São Gabriel). Foi realizada uma segunda adubação na razão de $36 \mathrm{~kg} \cdot$ ha $^{-1}$ de nitrogênio e $12 \mathrm{~kg} \cdot$ ha $^{-1}$ de potássio em $1^{\circ}$ de setembro de 2000. 
TABELA 1 - Datas de geadas ocorridas, com temperaturas mínimas e médias, em graus Celsius, entre os meses de maio e setembro do ano 2000, observadas na Estação Meteorológica de Entre Rios, Guarapuava, PR, 2002.

\begin{tabular}{llcc}
\hline Mês & Dia & $\mathrm{T}\left({ }^{\circ} \mathrm{C}\right)$ Mínima & T (ㅇ) Média \\
\hline \multirow{4}{*}{ Maio } & 07 & 3,4 & 11,1 \\
& 09 & 3,8 & 11,8 \\
& 28 & 0,8 & 7,8 \\
\hline Junho & 29 & 1,4 & 8,9 \\
\hline \multirow{4}{*}{ Julho } & 22 & 2,0 & 9,6 \\
& $12^{*}$ & 0,4 & 1,4 \\
& 13 & $-2,6$ & 6,8 \\
& 14 & $-4,4$ & 5,8 \\
& 16 & $-1,0$ & 1,0 \\
& 17 & $-7,6$ & 2,2 \\
& 18 & $-1,6$ & 5,1 \\
& 20 & $-4,0$ & 4,0 \\
Agosto & 21 & $-0,8$ & 9,5 \\
& 24 & $-2,8$ & 5,2 \\
Setembro & 25 & 1,8 & 9,4 \\
\hline
\end{tabular}

${ }^{*}$ Neve.

**Não ocorreu geada - nublado e vento.

Obs: Dia 10 de Setembro - intensa chuva de granizo.

TABELA 2 - Características químicas do solo antes de instalar o experimento. Candói - PR, 2002.

\begin{tabular}{|c|c|c|c|c|c|c|c|c|c|}
\hline Profundiade & $\mathrm{pH}$ & $\mathrm{MO}^{*}$ & $\mathrm{Al}^{+3}$ & $\mathrm{H}+\mathrm{Al}$ & $\mathrm{Ca}$ & $\mathrm{Mg}$ & $\mathrm{K}$ & $\mathrm{P}$ & $\mathrm{V}^{\star \star}$ \\
\hline $\mathrm{Cm}$ & $\mathrm{CaCl}_{2}$ & g.dm ${ }^{-3}$ & {$[\ldots \ldots \ldots$} & (r) & nolc.dn & & .....] & Mg.dm ${ }^{-3}$ & $\%$ \\
\hline $0,0-5,0$ & 5,6 & 52,00 & $<1$ & 34,0 & 53,0 & 33,0 & 3,7 & 13,0 & 73,0 \\
\hline $5,0-10,0$ & 5,5 & 48,00 & $<1$ & 44,0 & 49,0 & 32,0 & 3,0 & 8,0 & 66,0 \\
\hline $10,0-20,0$ & 5,2 & 49,00 & 2,00 & 55,0 & 26,0 & 16,0 & 1,9 & 6,0 & 37,0 \\
\hline
\end{tabular}

*Matéria orgânica

**Saturação de bases

O método de pastejo empregado no experimento foi o contínuo, com carga variável, para manter uma oferta de forragem pretendida de $10 \%$ (10 kg MS.100 kg PV $\left.{ }^{-1}\right)$, utilizando-se a técnica putand-take, descrita por Mott e Lucas (1952).

A estimativa da disponibilidade de matéria seca $\left(\mathrm{kg} \mathrm{ha}^{-1}\right)$ da pensacola foi realizada mediante a metodologia apresentada por Tothill et al. (1978) denominada Botanal, acrescida das melhorias sugeridas por Jones et al. (1979). Foram realizadas no total 4 avaliações (em 08/12/00, 09/02/01, 06/06/ 01 e 20/12/01).

Para a avaliação do comportamento da espécie estudada em relação às dosagens de glifosato, foi efetuada a análise de regressão por meio de modelos polinomiais de $2^{\circ}$ grau. Cada época foi analisada separadamente.

\section{RESULTADOS E DISCUSSÃO}

As relações entre a participação da pensacola (Paspalum notatum var. saurae) na matéria seca disponível (MSd) e as dosagens de glifosato, para as quatro datas avaliadas 08/12/00, 09/02/01, 06/06/01 e 20/12/01 estão expressas na Figura 1, pela regressão quadrática.

A pensacola foi visivelmente controlada pela geada e pelo glifosato, demonstrando sensibilidade a esses fatores. Ferri (1997) encontrou como significativa a relação \% de cobertura de Paspalum e doses glifosato. Desta forma, a pensacola deu condições para as espécies sobre-semeadas estabelecerem-se na área. Em 08/12/00 (Figura 1), observou-se que, possivelmente, o efeito sinérgico da geada sobre os tratamentos tenha sido o fator principal para a baixa participação da pensacola na quantidade de MSd, neste primeiro verão, após a sobresemeadura. O tratamento em que houve maior participação da pensacola na MSd, foi o T1 (sem herbicida) $(28,95 \%)$. Foi também, o tratamento que menos favoreceu o desenvolvimento de espécies indesejáveis no campo naturalizado, tais como a Eleusine indica, Senecio brasiliensis, Eryngium panniculatum, Sida rhombifolia e outras.

$\mathrm{Na}$ segunda avaliação, em 09/02/01, a pensacola na MSd variou de $22,40 \%$ (T4) a $46,28 \%$ (T5). Não era esperado que o T5 (1,25 L.ha-1 $)$, com maior dose de glifosato, proporcionasse o maior retorno da pensacola quando comparado aos outros tratamentos. 


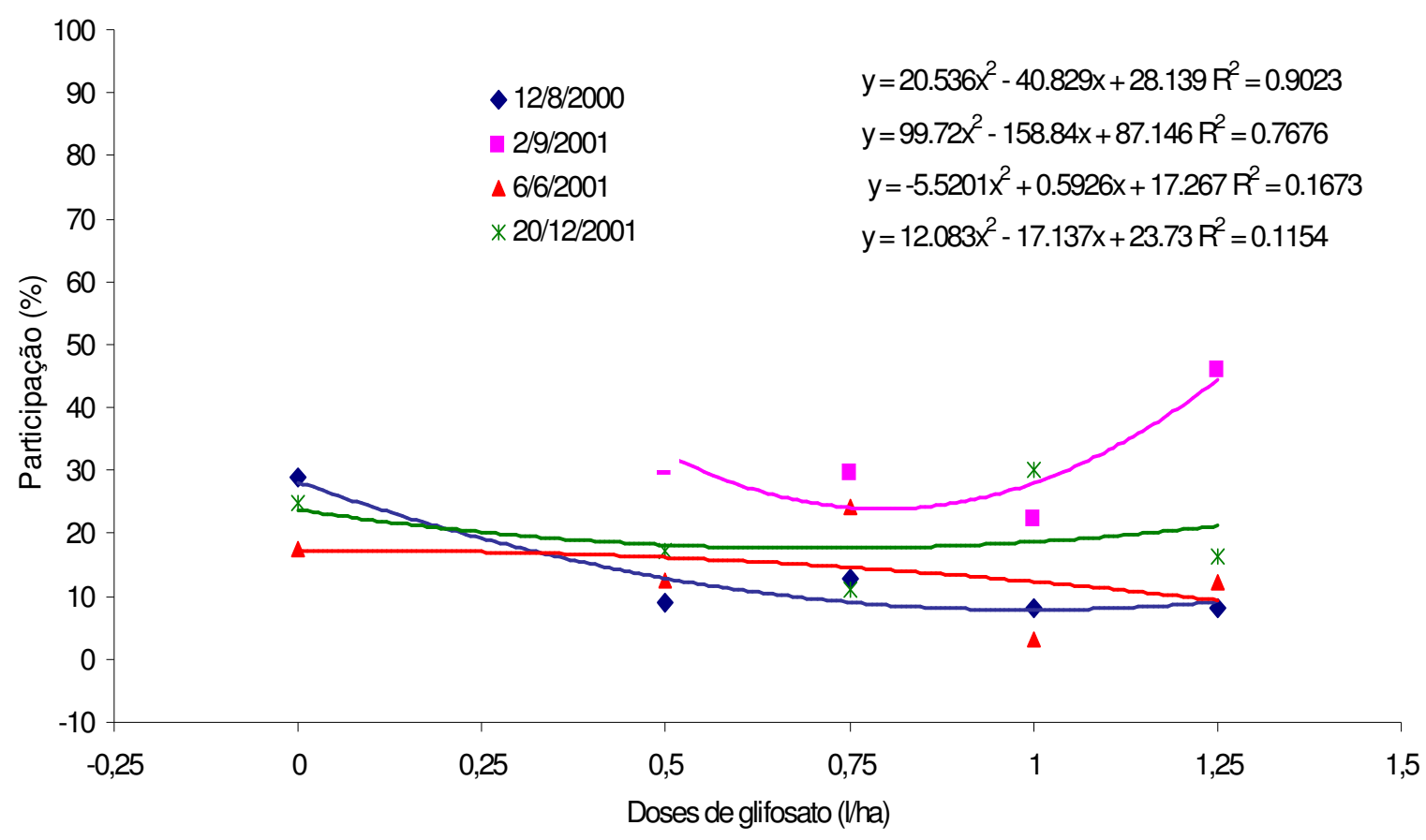

FIGURA 1 - Participação da pensacola nas datas avaliadas, na matéria seca disponível $\quad$ (MSd), em função das doses de glifosato aplicadas. Candói - PR, 2002.

Isto ocorreu provavelmente devido à localização desta unidade experimental, onde possivelmente a geada não foi tão severa, diminuindo o efeito do herbicida mais a geada e, consequentemente, favorecendo a detoxificação da planta, o que implicou no maior retorno da pensacola ao campo naturalizado e prejudicando o estabelecimento, nesta época, das espécies sobresemeadas; o T4 (1,0 L.ha-1) foi o que menos teve participação da pensacola na MSd, dando lugar ao aparecimento de gramíneas com menor valor forrageiro. Não foi possível avaliar o T1. A pastagem não havia se recuperado das geadas, apresentando apenas matéria morta.

Um ano após a sobre-semeadura, em 06/06/ 01 a participação da pensacola na MSd variou de $3,16 \%$ a $24,25 \%$, correspondendo ao tratamento 4 $\left(1,0\right.$ L.ha $\left.^{-1}\right)$ e $3\left(0,75\right.$ L.ha $\left.^{-1}\right)$ respectivamente. A participação da pensacola diminuiu nesta época e foi notável a participação das espécies sobre-semeadas na MSd do campo naturalizado. Com exceção do tratamento 4 , todos os outros tratamentos, inclusive o T1 (sem herbicida), apresentaram valores similares ao T3, para a pensacola. Provavelmente, em 06/06/ 01, o controle da pensacola se deu por competição com as espécies introduzidas. No tratamento 4, onde a geada aparentemente foi mais severa, em razão da localização das parcelas experimentais (região mais baixa do terreno), e o efeito do herbicida mais a geada foi mais grave na pensacola, as espécies sobresemeadas retornaram com mais rapidez e promoveram maior sombreamento à pensacola e cobertura e a seu banco de sementes, respectivamente, concordando com os resultados obtidos na época anterior, em 09/02/01.

No final da primavera, em 20/12/01, aproximadamente um ano e meio após a sobresemeadura, esperava-se encontrar novamente a pensacola no campo, com vigor e significativa participação na MSd. Esta participação da pensacola variou de $11,06 \%$ a $30,04 \%$ para o tratamento $3(0,75$ L.ha- $\left.^{-1}\right)$ e 4 (1,0 L.ha-1 ${ }^{-1}$ respectivamente. Estes valores foram inversos aos encontrados na avaliação realizada em 06/06/01. Observando a participação da pensacola no tratamento1 (sem herbicida), de $24,68 \%$, nota-se a dificuldade que a pensacola teve em retornar à composição botânica nas áreas onde foram introduzidas as espécies. A competição por luz e o efeito da cobertura do solo podem ter sido os fatores que diminuiram a participação da pensacola na MSd do campo naturalizado. Ferri, (1997) verificou que a cobertura proporcionada pela cultura reduziu o desenvolvimento do Paspalum notatum, mostrando que este gênero é sensível ao sombreamento.

A principal função do herbicida na sobresemeadura foi reduzir a competição entre as espécies sobre-semeadas e as espécies preexistentes do campo. Este experimento foi instalado na estação do ano sujeita às geadas severas, e os dados coletados neste experimento apontam a suficiência da geada em controlar a pensacola para a introdução, em sobresemeadura, de espécies exóticas. 
Os resultados obtidos neste trabalho não confirmaram a hipótese na sua totalidade. É certo que o herbicida de ação sistêmica controla a vegetação existente, mas revela tendências de, em uso contínuo, eliminar alguma espécie do campo naturalizado. É importante observar alguns dados retirados deste experimento, no que diz respeito ao tipo de herbicida e às doses utilizadas. $O$ efeito promovido pela geada no experimento, especialmente com o T1 (sem herbicida e com sobre-semeadura+adubo), foi suficiente para controlar a competição oferecida pela pensacola às espécies sobre-semeadas. A geada também possibilitou o restabelecimento da pensacola no verão. Em vista disto, os dados sugerem a importância da introdução de tratamentos nestes estudos em regiões sujeitas às geadas, com herbicidas pós-emergentes, de contato, não seletivos e sem efeito residual, que possam simular o efeito da geada em regiões onde não sejam beneficiadas com este fenômeno na época que antecede a sobre-semeadura.

\section{CONCLUSÕES}

O herbicida glifosato influenciou a participação da pensacola no campo naturalizado sob ação da geada, e não comprometeu seu restabelecimento no verão.

A ação da geada foi suficiente para controlar a pensacola na época que antecede a sobre-semeadura.

\section{AGRADECIMENTOS}

Aos colegas Rodolpho Botelho e Simone Gugelmin.

\section{REFERÊNCIAS}

1. BALL, D. M.; HOVELAND, C. S.; LACEFIELD, G. D. Southern forages, Atlanta, 1991. 256p.

2. COMISSÃO DE FERTILIDADE DO SOLO-RS/SC. Recomendação de adubação e calagem para os estados do Rio Grande do Sul e Santa Catarina. 3a ed. Passo Fundo, SBCS - Núcleo Regional Sul/EMBRAPA/CNPT. 224 p., 1995.

3. EMBRAPA Centro Nacional de Classificação de Solos. Sistema brasileiro de classificação de solos. Rio de Janeiro: EMBRAPA Solos, 1999. $412 \mathrm{p}$.

4. FERRI, M. V. W. Semeadura direta de soja e aveia em campo nativo dessecado com herbicidas. Santa Maria, 1997. 106p. Dissertação (Mestrado em Agronomia) - Universidade Federal de Santa Maria.

5. IAPAR - INSTITUTO AGRONÔMICO DO PARANÁ. Cartas Climáticas do Estado do Paraná 1994. Londrina: IAPAR. 49p., 1994. (Documento, 18).

6. JONES, R. M.; HARGREAVES, J. N. G. Improvements to the dry-weight-rank method for measuring botanical composition. Grass and forage science. Oxford. V.34, p.181-189, 1979.

7. MAAK, R. Geografia física do Estado do Paraná. Curitiba: Banco de Desenvolvimento do Paraná - BADEP. 1968. 350p.

8. MACEDO, M. C. M. Integração lavoura-pecuária: alternativa para a sustentabilidade da produção animal. In: SIMPÓSIO DE MANEJO DE PASTAGENS: Planejamento de sistema de produção em pastagens, 18., 2001, Piracicaba. Anais. Piracicaba: FEALQ, 2001, p. 257.

9. MOTT, G. O.; LUCAS, H. L. The design, conduct and intrepretation of grazing trials on cultivated and inproved pastures. In: INTERNATIONAL GRASSLAND CONGRESS, 6., 1952, Pensylvania. Procedings, Pensylvania: State College Press, p.1380$1385,1952$.

10. REIS, R. A.; FONTANELI, R. S. Melhoramento de pastagens através de introdução de forrageiras de inverno visando maximizar o uso do solo. In: SIMPÓSIO DE FORRAGICULTURAE PASTAGENS. 2000, Lavras. Anais. Lavras: Universidade Federal de Lavras, 2000, p.237-271.

11. RIZO, L. M. Avaliação de pastagem natural e pastagem natural sobre-semeada com e sem o uso do herbicida glifosato. Santa Maria, 2001. 103f. Dissertação (Mestrado em Zootecnia) - Universidade Federal de Santa Maria.

12. SIMEPAR - Sistema Meteorológico do Paraná. Disponível em: <http://www.simepar.br/>Acesso em julho de 2002.

13. TOTHILL, J. C.; HARGREAVES, J. N.; JONES, R. M. Botanal: A comprehensive sampling and computing method for estimating pasture yield and composition. In: Field sampling. Brisbane, CSIRO, Division of Tropical Crops and Pastures, Tropical Agronomy 1978. 20p. (Tropical Agronomy Technical Memorandum, n.8).

14. VINCENZI, M. L. Fatores essenciais para o sucesso da sobre-semeadura de espécies de inverno em campos naturais e naturalizados. In: REUNIÃO DO GRUPO TÉCNICO EM FORRAGEIRAS DO CONE SUL - ZONA DE CAMPOS, 17., 1998, Lages. Anais. Lages: Epagri/UDESC, 1998, p.29-37. 